\title{
THE CORROSION OF METAL BY PALMAR SWEAT
}

\author{
BY \\ K. J. COLLINS \\ From the Medical Research Council Unit for Research on Climate and Working Efficiency, Department of Human
Anatomy, University Museum, Oxford
}

(RECEIVED FOR PUBLICATION JANUARY 30, 1957)

The problem of metal corrosion resulting from contamination by palmar sweat is common to many industrial occupations. Constant handling of metal parts by some individuals causes an accumulation of rust (Fig. 1). In the manufacture of highlyfinished metal products, for example ball-bearings, and also in subsequent assembling and packing processes, serious consideration must be given to this effect. Frequently, operators are required to wear gloves during stages of manufacture involving the handling of metal. Where the nature of the work militates against the use of mechanical safeguards it is sometimes necessary to make preliminary tests in order to exclude individuals who are found to produce marked corrosion by handling.

The corrosive nature of sweat has been known for some time (Yerbury, 1919; Huff, 1921) but few objective investigations on this subject have appeared. Tools cannot be protected by greasing unless all traces of sweat are first removed. Several cleansing agents for removing sweat residues have,

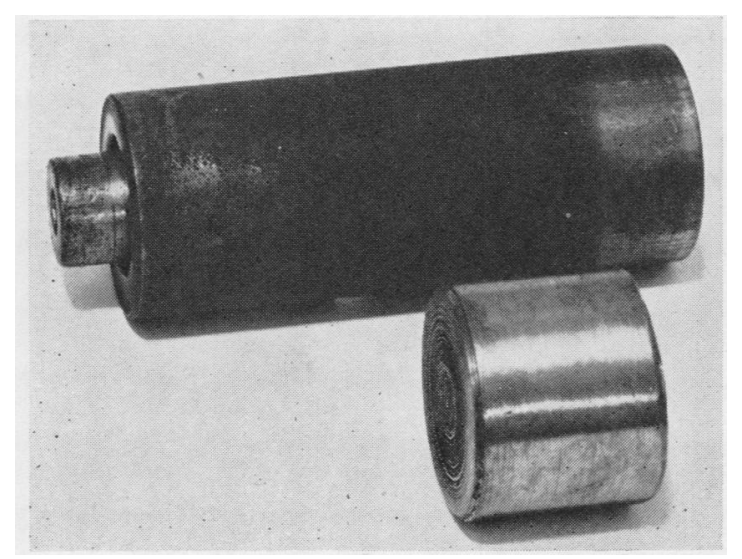

FIG. 1.-Machine tool corroded by several days' handling compared with specimen of unhandled mild steel. however, been described (Beuerlein, 1941; Clarke and Longhurst, 1951; B.S. 1133 Packaging Code, Section 6, 1953; Eisler and Faigen, 1954).

Rusting after contamination by sweat is a particular example of atmospheric corrosion. Vernon (1935) made a careful study of factors which influence this type of corrosion and has shown that a freshlypolished metal surface is more susceptible to attack than a surface retaining its protective oxide film. Atmospheric corrosion is also influenced by the relative humidity of the environment to which the metal is exposed and by the presence of solid contaminants, such as particles of salts. Urmeev (1941) suggested that the amount of corrosion on metal tools which have been contaminated by sweat depends on the sodium chloride content of sweat and on the humidity of the air but not on the presence of organic acids.

Palmar (and plantar) sweat glands react primarily to mental or emotional stimuli (Kuno, 1956), and for this reason variations in palmar sweating are less predictable than sweating from other areas on the general body surface where the glands respond mostly to thermal stimuli. From experiments made in this laboratory it was apparent that the considerable differences in corrosion produced by different subjects were related to the activity of the palmar sweat glands. The following description of the phenomenon in terms of physiological observations on the activity of palmar sweat glands and sweat composition may therefore be of value in assessing methods suitable for eliminating this effect in given circumstances.

\section{Methods and Materials}

Analysis and Preparation of Metal Specimens.Specimens used in palmar and finger print tests were $2.0 \times 2.0 \times 0.1 \mathrm{~cm}$., weighing approximately $2.5 \mathrm{~g}$. each, and for spray tests $3.0 \times 5.0 \times 0.1 \mathrm{~cm}$., weighing approximately $11.0 \mathrm{~g}$. each. All were cut from the same mildsteel sheet, an analysis of which resulted as follows: 


$\begin{array}{lllll}\text { Carbon } & . & \ldots & \ldots & 0.07 \% \\ \text { Sulphur } & \ldots & \ldots & \ldots & \mathbf{0 . 0 6 \%} \\ \text { Phosphorus } & . & \ldots & \ldots & 0.03 \% \\ \text { Manganese } & \ldots & \ldots & \ldots & 0.31 \% \\ \text { Copper } & . & \ldots & \ldots & 0.06 \% \\ \text { Silica } & . & \ldots & \ldots & 0.01 \%\end{array}$

A standard procedure for preparing the metal specimens was used throughout and contamination by handling was avoided by means of greaseproof-paper and forceps.

(a) Specimens were ground on a grit linisher. (b) The lines of the linisher were obliterated by rubbing by hand with Oakey No. 1 emery cloth and then with Oakey No. 0 emery cloth. (c) This was followed by two washings in A.R. benzene, swabbing meanwhile with cotton-wool. (d) After a third washing in A.R. benzene the wet surfaces were wiped clean with filter-paper to remove emery residues. (e) All specimens were dried overnight in a vacuum desiccator before use.

Exposure of Metal after Contamination.-Contaminated specimens were placed in a sealed glass vessel for one week at a temperature of $25^{\circ} \mathrm{C}$. and relative humidity of $87 \%$, obtained by placing a saturated aqueous solution of sodium carbonate in the base of the vessel. Oxygen in the vessel was replenished by opening each day. The metal specimens were suspended inside the vessel between clean, thin glass rods.

A high relative humidity was deliberately chosen in order to facilitate the measurement of corrosion on specimens. The amount of corrosion after exposure to lower humidities was often found to be negligible. At approximately $80 \%$ R.H. (the " secondary critical humidity" for steel) there is a large increase in corrosion rate and this is accelerated by contaminants on the metal surface.

Palmar Corrosion Tests.-Before these tests, the palms were carefully washed $(a)$ for two to three min. under warm running water without soap, (b) for two to three min. in warm distilled water, $(c)$ thoroughly dried by means of clean tissue.

Palmar contamination tests were performed by placing a metal specimen, previously weighed on a microbalance, lightly in contact with the proximal part of the thenar eminence of the palm for five min. Finger print contamination was measured also over five min. with light pressure on weighed specimens. The metal was then exposed for one week at $25^{\circ}$ C. and $87 \%$ R.H., dried for 24 hours in a vacuum desiccator, and reweighed on the microbalance.

The increase in weight of the metal due to sebum and epithelial debris adhering to the surface was determined by drying a control specimen for $24 \mathrm{hr}$. in vacuo after contamination, and then re-weighing.

Measurement of Sweat Rate and Skin pH.-Palmar sweat rates were determined for each subject immediately following contamination tests. A metal capsule, $15 \mathrm{sq} . \mathrm{cm}$. in area, enclosing anhydrous calcium chloride in a gauze pad was placed in firm contact with the proximal part of the thenar eminence for $10 \mathrm{~min}$. The weight of sensible and insensible perspiration absorbed by the calcium chloride during this period was then obtained.

The $p \mathrm{H}$ on the surface of the palm was measured by a method essentially similar to that described by Blank (1939) and Anderson (1951). The skin surface was prepared by cleaning with A.R. ethyl ether and then moistened with a thin film of $0.1 \% \mathrm{NaCl}$ solution at pH 5.0. A miniature sealed-glass electrode was placed in firm contact with the skin $1 \mathrm{~cm}$. from a calomel reference electrode. About eight readings were taken on the midpalm region using a Cambridge direct-reading $p \mathrm{H}$ meter with temperature adjustment to $30^{\circ} \mathrm{C}$. A mean value for each subject was taken from the last four readings.

Spray Tests.-The corrosive properties of aqueous solutions of known constituents of sweat were compared. Duplicate specimens $(3 \times 5 \times 0.1 \mathrm{~cm}$. $)$ were used throughout. Each weighed specimen was supported vertically in a wooden frame mounted at the end of a tunnel and at exactly $40 \mathrm{~cm}$. from the nozzle of an "aerograph" spray. The edges of the metal were shielded by the wooden frame so that an area of $11 \mathrm{sq}$. $\mathrm{cm}$. was exposed to the spray. Each side of the metal was sprayed horizontally for five sec. at a constant pressure of $35 \mathrm{lb}$./sq.in.

Immediately after spraying, specimens were placed in an environment maintained at $25^{\circ} \mathrm{C}$. and $87 \% \mathrm{R}$.H. for one week. After this time they were removed, dried overnight in vacuo, and the gain in weight of each specimen determined by re-weighing. Weight loss was then measured by treating the specimen cathodically in $10 \%$ sodium cyanide solution at room temperature and at a current density of $1 \mathrm{amp} / \mathrm{dm}^{2}$. Removal of rust was completed in six min. for all specimens. After cathodic treatment, the metal was scrubbed with a fibre brush under cold running water. Then the metal was rinsed in hot water, dried by clean filter paper, and finally dried overnight in vacuo before re-weighing.

\section{Results}

Corrosion by Different Individuals.-Eight male subjects selected at random for preliminary experiments were asked to wear a rubber glove into each of which was inserted a small cylinder of degreased, polished mild steel. After one and a half hours, four of the subjects were found to have corroded the metal heavily and in addition had rust-stained hands, two produced slight tarnishing and two had a negligible effect. It appears that some individuals may handle degreased metal without having any effect while others produce heavy accumulations of rust.

The amount of corrosion by palmar sweat from one subject was not constant but varied widely at different times, e.g., subject $\mathrm{A}$ in Table 1 . Under the experimental conditions in contamination tests, corrosion proceeded rapidly on exposure of the metal to $25^{\circ} \mathrm{C}$ and $87 \%$ R.H. After exposure for one week, threads of corrosion product appeared to have spread from nuclei on the surface of the metal (Fig. 2), a phenomenon which has been described as " filiform" corrosion (Sharman, 1944).

Of the four female subjects who were tested, two produced quite severe rusting and two had almost 
TABLE 1

CORROSION OF MILD STEEL BY PALMAR AND FINGER-TIP SWEAT

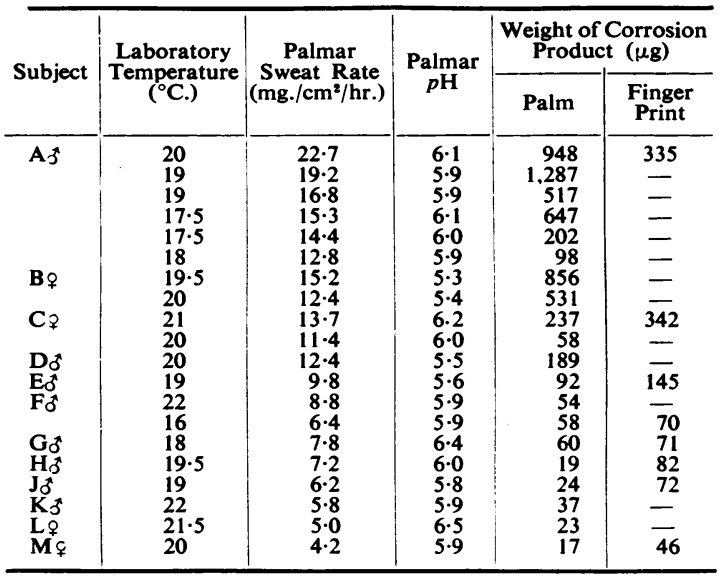

A correction has been applied to the weights of corrosion products given in the last two columns by subtracting the weight of dry debris adhering to the metal after contamination. This was usually negligible at low palmar sweat rates increasing to approximately $40 \mu \mathrm{g}$. at the highest sweat rates.

Mean increase in weight of control specimens was $18 \mu \mathrm{g}$.

no effect. There was no evident tendency for female subjects to produce more rusting than males by palmar contamination though no statistical comparison could be made with so few subjects.
Palmar Sweat Gland Activity.-The relationship between palmar sweat rate and the extent of corrosion of mild steel is shown in Fig. 3. The amounts of corrosion measured in these experiments after exposure to $87 \%$ R.H. are, of course, greater than would be expected in most normal working environments.

The increment in weight of the specimen due to rusting is nevertheless slight when a palmar sweat rate as measured by the calcium chloride capsule method is low $\left(4-10 \mathrm{mg} / \mathrm{cm} .{ }^{2} / \mathrm{hr}\right.$.). When sweating increased so that the palmar sweat rate exceeded $10 \mathrm{mg} . / \mathrm{cm} .{ }^{2} / \mathrm{hr}$. corrosion became much more severe and fluctuations between individual values more marked.

Fingerprints usually contaminated about $2 \mathrm{sq} . \mathrm{cm}$. of the metal surface, whereas in palmar tests the entire surface on one side of the metal specimen (4 sq. cm.) was affected. However, in all cases with the exception of subject A (Table 1) the amount of corrosion from fingerprints exceeded that measured simultaneously from the thenar eminence of the same palm.

Although palmar sweating is essentially " mental" sweating, the amount of sweating and subsequent corrosion was invariably diminished at environmental temperatures lower than normal. The reduction in palmar sweat rate was presumably the result of a reduction in skin temperature.

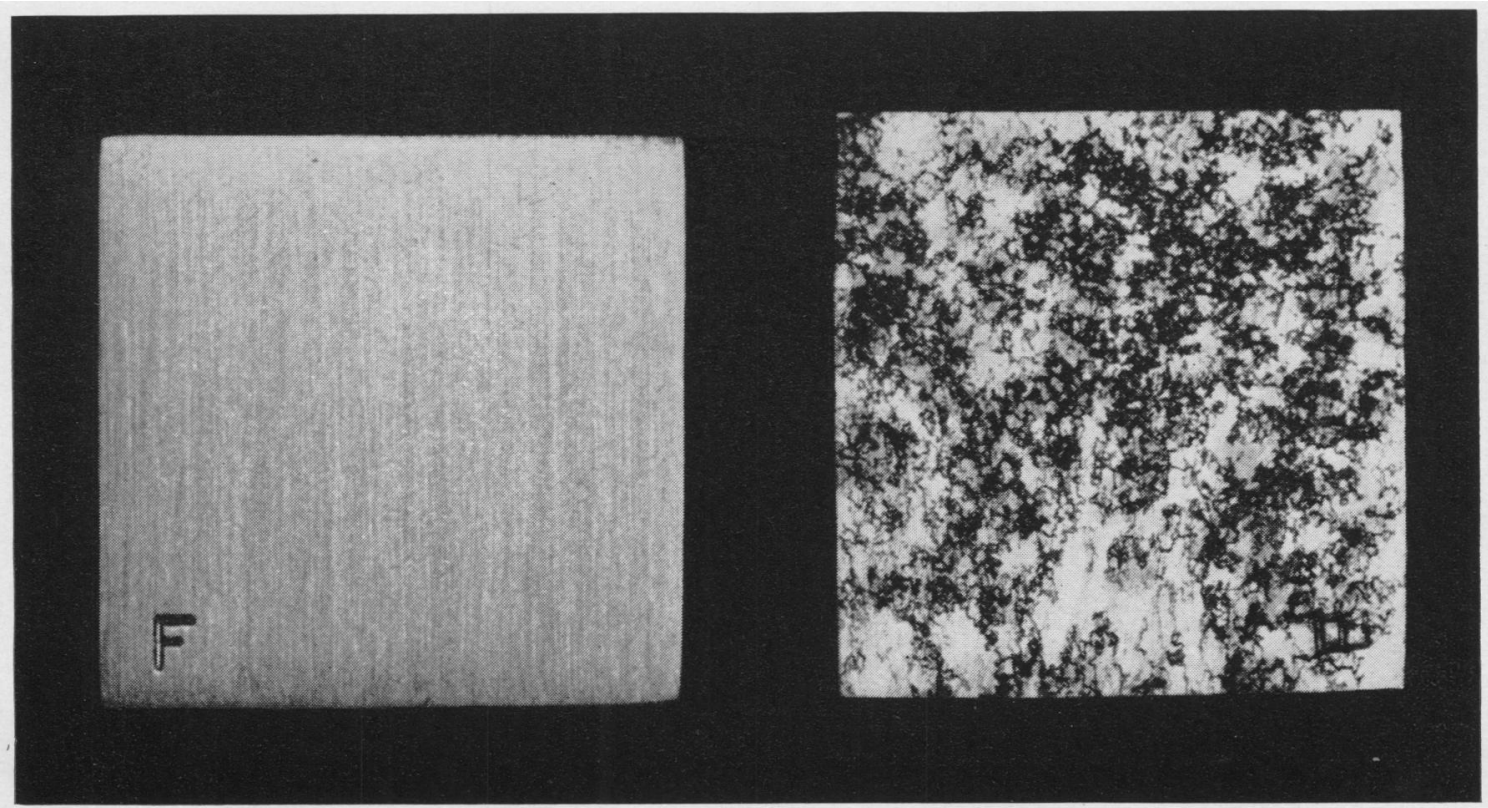

(i)

(ii)

FIG. 2.-Mild steel specimens $\left(2 \cdot 0 \mathrm{~cm}^{2}\right)$ : (i) control; (ii) rusted specimen after palmar contamination (subject A) and exposure for one week to $25^{\circ}$ C. and $87 \%$ R.H. 
Fig. 3.- The relation between palmar sweat-rate and corrosion of mild steel after exposure of specimens to $25^{\circ} \mathrm{C}$. and $87 \%$ R.H. for one week following contamination.

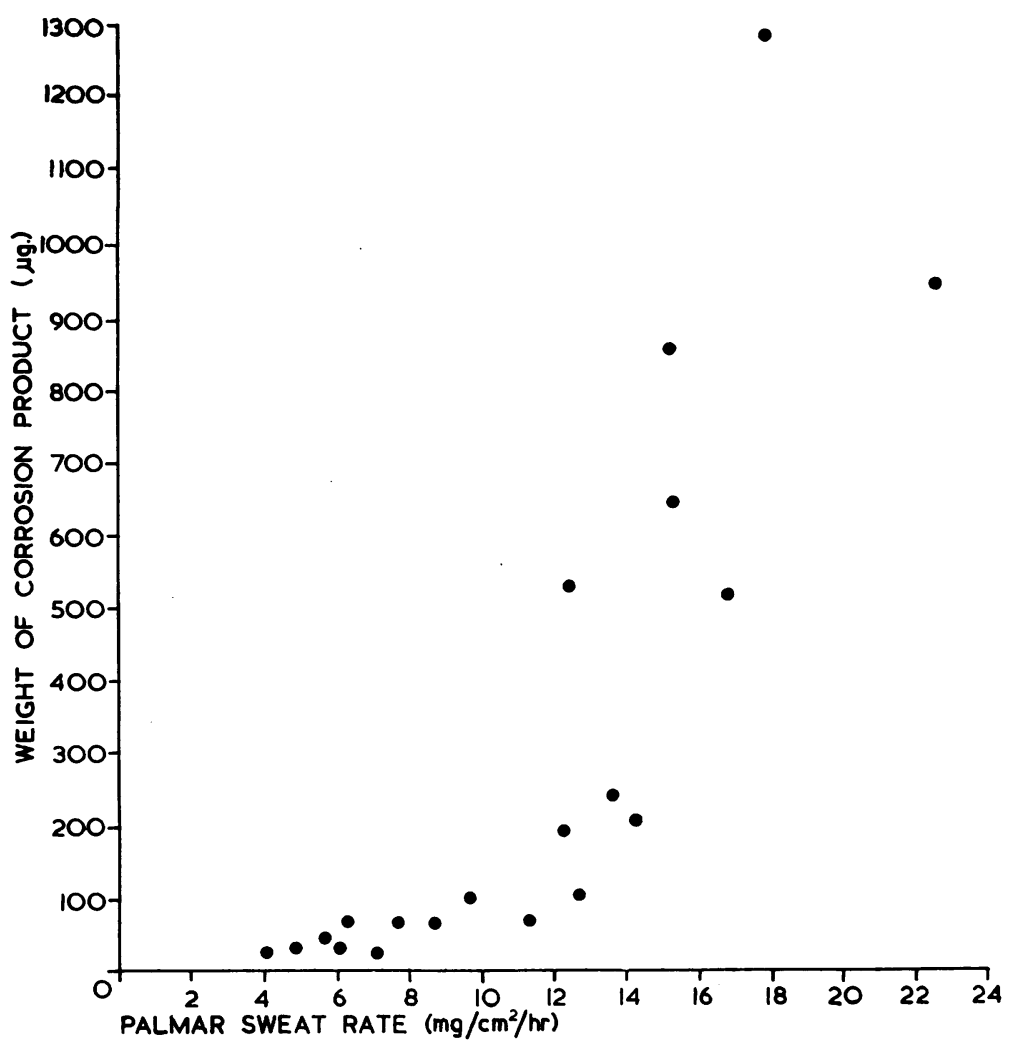

" intermittent" type of sweating. The results in Table 2 show that the sodium chloride content of palmar sweat can account for a high proportion of the corrosive action. Other inorganic substances probably also take some part in the electrolytic corrosion process but these are in much smaller concentration than sodium and chloride. The mean concentration of potassium in "thermal " sweat is reported to be $18 \mathrm{mg} . \%$ (Robinson and Robinson, 1954). Urea and lactic acid, which are normally present in next highest concentration to sodium chloride, each produce less than $5 \%$ of the amount of corrosion caused by an equal concentration of sodium chloride (Table 2). In " thermal" sweat, Robinson and Robinson (1954) quote values of 36 to $360 \mathrm{mg}$ \% lactic acid and 32 to $196 \mathrm{mg} . \%$ total nitrogen while Lobitz and Osterberg (1947b), and Lobitz and Mason (1948a, b) have found mean values of 68 to $275 \mathrm{mg}$. \% urea, 8 to $26 \mathrm{mg}$. \%

Composition of Palmar Sweat.-A comparison of the corrosive properties of constituents of palmar sweat has been made by spray tests (Table 2). Available data on the composition of palmar sweat is conflicting but the probable range of the most important constituents are included in the spray tests. Both gain in weight after corrosion and loss in weight following the removal of the corrosion product are measured. Loss in weight is probably the more reliable since it gives a direct measurement of the weight of metal corroded.

Sweat is a hypotonic solution containing 0.5 to $1 \%$ solids, the most important solute being sodium chloride. Darling (1948) found that the mean chloride content of palmar sweat was $108 \mathrm{mg} . \%$. (The sodium concentration in sweat of normal men is usually approximately the same as the chloride concentration.) On the other hand, the muchquoted results of Lobitz and Osterberg (1947a) give higher values for sodium chloride in palmar sweat with $385 \mathrm{mg}$. $\mathrm{NaCl} \%$ as mean value for " profuse" type of sweating, and $1,091 \mathrm{mg}$. $\mathrm{NaCl} \%$ for the ammonia nitrogen, and 0.5 to $1.3 \mathrm{mg} . \%$ creatinine in palmar sweat.

The addition of lactic or butyric acids to a solution of $500 \mathrm{mg} . \%$ sodium chloride produced an increase in the amount of corrosion compared with that caused by the sodium chloride solution alone. When an emulsion of oleic acid in water was added to the sodium chloride solution, a smaller increase in corrosion as measured by weight loss was observed. This appears to be in agreement with the results of Ŝmiałowski and Ostrowska (1954) who find that the extent to which stress corrosion cracking in steel is inhibited by fatty acids depends on the length of the hydrocarbon chain.

It would be difficult to decide from the figures in Table 1 whether the amount of corrosion is also related to the $p \mathrm{H}$ of the surface aqueous layer of the palm because of the overwhelming effects of sweat-rate and the differences in salt content of sweat. The $p \mathrm{H}$ of the palmar surface of the subjects investigated was always on the acid side, ranging from 5.3 to 6.5 with a mean value of 5.9 . 
TABLE 2

CORROSION OF MILD STEEL SPECIMENS BY VARIOUS SOLUTIONS (SPRAY TESTS)

\begin{tabular}{|c|c|c|}
\hline Solution & $\begin{array}{l}\text { Mean Weight Gain } \\
\text { of Specimens after } \\
\text { Corrosion (mg.) }\end{array}$ & $\begin{array}{l}\text { Mean Weight Loss } \\
\text { of Specimens after } \\
\text { Removal of Cor- } \\
\text { rosion Product (mg.) }\end{array}$ \\
\hline \multirow{6}{*}{ 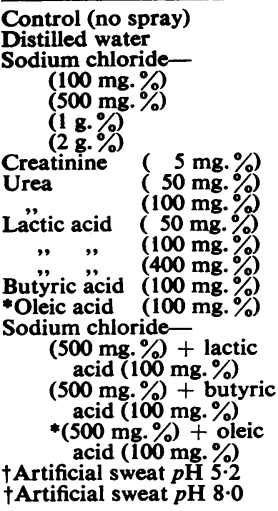 } & $\begin{array}{l}0.09( \pm 0.03) \\
0.25( \pm 0.05)\end{array}$ & $\begin{array}{l}0.27( \pm 0.04) \\
0.39( \pm 0.05)\end{array}$ \\
\hline & $\begin{array}{r}10.85( \pm 0.01) \\
16.05( \pm 0.70) \\
21.85( \pm 0.57) \\
31.00( \pm 0.55) \\
0.27( \pm 0.01) \\
0.34( \pm 0.05)\end{array}$ & $\begin{array}{r}13.98( \pm 0.46) \\
22.58( \pm 0.43) \\
28.39( \pm 0.96) \\
37.93( \pm 0.44) \\
0.36( \pm 0.01) \\
0.39( \pm 0.02)\end{array}$ \\
\hline & $\begin{array}{l}0.28( \pm 0.08) \\
0.30( \pm 0.01) \\
0.38( \pm 0.04) \\
0.41( \pm 0.05) \\
0.47( \pm 0.04)\end{array}$ & $\begin{array}{l}0.47( \pm 0.08) \\
0.37( \pm 0.03) \\
0.33( \pm 0.05) \\
0.55( \pm 0.04) \\
0.65( \pm 0.05)\end{array}$ \\
\hline & $17.69( \pm 0.79)$ & $24.92( \pm 0.92)$ \\
\hline & $17.09( \pm 0.68)$ & $24 \cdot 78( \pm 1 \cdot 03)$ \\
\hline & $\begin{array}{l}15.47( \pm 0.20) \\
17.68( \pm 0.61) \\
16 \cdot 28( \pm 0.31)\end{array}$ & $\begin{array}{l}23.42( \pm 0.81) \\
26.02( \pm 0.90) \\
24.38( \pm 0.29)\end{array}$ \\
\hline
\end{tabular}

*Water emulsion.

+ Artificial sweat solution: $\begin{array}{ll}\text { Sodium chloride } & (500 \mathrm{mg} . \%) \\ \text { Lactic acid } & (100 \mathrm{mg} \%) \\ \text { Urea } & (100 \mathrm{mg} \%) \\ p \mathrm{H} \text { adjusted by ammonium hydroxide solution. }\end{array}$

This is in the range reported by other workers for the palm (Lobitz and Osterberg, 1945; Anderson, 1951). Wide variations of $p \mathrm{H}$, however, seem unlikely because of the buffering capacity of the palmar surface. An artificial sweat solution composed of sodium chloride $(500 \mathrm{mg} . \%)$, urea (100 mg. $\%$ ), and lactic acid (100 mg. \%), was found to corrode more at $p \mathrm{H} 5 \cdot 2$ than at $p \mathrm{H} 8.0$ (Table 2). Eisler and Faigen (1954) also find that acidic synthetic fingerprint solutions produce greater corrosion than alkaline.

Skin Surface and Effect of Barrier Creams.-The skin surface probably consists of a fine emulsion of an aqueous and a lipid phase. Although sebaceous glands are not present on the palm, sebum is almost certainly there as a result of contamination, for example, from the forehead. The presence of surface fats and long-chain fatty acids may inhibit corrosion by palmar sweat. A comparison was therefore made of the amount of corrosion on metal specimens caused $(a)$ by the palmar surface retaining its fats and $(b)$ by the opposite palm from which surface fats had been removed by A.R. ethyl ether. The lowering of the skin temperature after the application of ether probably inhibited sweating and so an interval of time was allowed before the tests for the skin temperature of both palms to equalize. It was found that at low palmar sweat rates more corrosion appeared to result from contact with the palmar surface from which the fats had been removed. At high palmar sweat rates, however, corrosion was equally marked from contact with both normal and " defatted" palms.

Tests were also made to determine whether barrier creams could be used to reduce palmar sweat corrosion. Subjects were instructed to grip lightly, but with constant pressure, polished mildsteel cylinders which were placed in each hand for $10 \mathrm{~min}$. Before the test an application of one of three barrier cream preparations was made to one hand, the other hand acting as a control. The preparations used were: (1) A greasy barrier cream with petroleum-jelly base; (2) a non-greasy oil-inwater emulsion barrier cream; (3) a silicone emulsion barrier cream.

After the test, the steel cylinders were kept at laboratory temperature for 24 hours and then carefully cleaned with A.R. benzene. Subjects with low palmar sweat rates produced slight corrosion of the metal and this was prevented by application of any one of the barrier creams. However, at high palmar sweat rates corrosion could be effectively reduced but not eliminated, preparations (1) and (3) being the most efficient.

\section{Prevention of Corrosion by Palmar Sweat}

No completely satisfactory method for preventing corrosion by palmar sweat is in general use though in particular circumstances some methods or combination of methods have been used effectively. Petroleum or chlorinated solvents will not remove water-soluble sweat contaminants. It is possible to remove sweat residues from metal surfaces by $95 \%$ methanol in water, oil-in-water emulsions, or aqueous alkaline cleaning processes (B.S. 1133 Packaging Code, 1953). Sweat must, however, be removed at once because atmospheric corrosion rapidly takes place. Corrosion by salts deposited on the bare metal will still occur under oil if oil is applied after contamination (Huff, 1921).

Simple precautions are usually taken in order to avoid contact with degreased metal, for example, by the use of gloves or handling with forceps. These expedients prevent corrosion but are impracticable in occupations where they may interfere with operations. Impervious rubber or P.V.C. gloves if worn for long periods may produce auto-maceration of the skin by sweat held inside the glove. Barrier creams certainly allow freedom of manipulation but the efficiency of these preparations is reduced by friction and the necessity for re-application. In our experience the greasy or silicone preparations appear to be the most effective but even these do not completely eliminate corrosion in the case of hyperhidrotic individuals with whom the most 
troublesome effects occur. Chemical substances which suppress local hyperhidrosis, e.g., Zn or Al salts, are unsuitable for regular use since they frequently cause skin irritation, especially with those who have an acquired sensitivity. Kuno (1956) describes the anti-sudorific effect of 7 to $10 \%$ formaldehyde which, iontophorized for 5 to $10 \mathrm{~min}$., produces local anhidrosis which lasts from 4 to 18 days. Formaldehyde, however, is a notorious skin sensitizer and its occasional use in industry, e.g., as a preservative in adhesives, has led to serious outbreaks of dermatitis. The toxic action which this treatment may have on the skin is a serious disadvantage although it is claimed that the method can be used on the palms or soles without damage.

\section{Discussion}

The differences displayed by individuals in the corrosive effect of palmar contact with metal can largely be explained in terms of the physiological characteristics of palmar sweating, the most important single factor probably being the amount of sweat produced.

Secretion of sweat from the palms (and soles) takes place continuously. Sweat glands are present most densely in these regions and insensible perspiration exceeds that from other areas on the general body surface (Kuno, 1956). Palmar sweating is provoked by emotion, uneasiness, or moderate pain. The activity of palmar sweat glands depends therefore to a great extent on the temperament of the subject and this is probably the main reason for the individual differences in corrosion. The palms of most people are usually dry, but small increases in sweating can be evoked by moderate mental stimulation. Some individuals appear to have moist palms and others produce abnormal amounts of sweat amounting to hyperhidrosis. When metal is handled by a hyperhidrotic subject severe corrosion ensues, e.g., in subject A. Kuno (1956) has shown that the protuberant regions of the palm, and particularly the finger-tips, sweat more profusely than the central part of the palm. Consequently finger print corrosion is usually more severe than that due to contamination by the palm itself (Table 1). These regional differences in surface sweat production are not found in hyperhidrotic states where sweat appears all over the palms. Finger print corrosion by subject $\mathrm{A}$ was therefore less than that from the palm because a smaller area was contaminated.

Enquiry from a number of industrial organizations has revealed that sweat from female employees is regarded as being more corrosive than that from males. This sex difference may possibly be due to differences in the emotional state of the employees.
In Table 1, where only a few subjects were examined, there is no clear distinction between sexes. However, MacKinnon (1954) has investigated the variations in the number of active palmar digital sweat glands during the human menstrual cycle and found a statistically significant decrease in the number of active glands during the luteal phase of the menstrual cycle. It may be inferred therefore that during the luteal phase female operators who handle metal will cause less corrosion than during the follicular phase of the menstrual cycle.

The activity of palmar sweat glands is influenced by environmental temperatures though this may not be due to direct thermal stimulation. At low temperatures, mental stimuli no longer cause an increase in palmar sweating (Kuno, 1956) and in the present experiments sweating was found to be partially inhibited at low laboratory temperatures. In hot environments, a decrease in the activity of palmar sweat glands has also been observed (Darling, 1948; Randall and Hertzmann, 1953; Hellon and Lind, 1956), although Kuno (1956) has reported that the activity of the glands did not decline in the heat but that mental stimulation in the heat did not increase palmar sweating. MacKinnon and MacKinnon (1956) have found that "basal palmar sweating" in female subjects decreased in summer although body temperatures in summer were higher than in winter. Palmar sweating may therefore be inhibited in extreme environmental temperatures by reduction of skin temperature in the cold and possibly by a decrease in "tonic" mental stimulation of the glands in heat. It is very likely, however, that the corrosion hazard in hot environments is increased because of " thermal " sweat from the arm spreading to the palm.

Most of the corrosive properties of sweat can be attributed to the sodium chloride content, the concentration of which may be extremely variable. A majority of investigators have found, at least for thermal sweat, that the chloride concentration varies directly with the rate of sweating (Robinson and Robinson, 1954). This relationship may, however, be secondary to the effect of skin temperature (Robinson, Gerking, Turrell, and Kincaid, 1950: Weiner and van Heyningen, 1952a) which in turn is largely dependent on environmental temperature. Darling (1948) found that the chloride content of palmar sweat is increased with a rise in skin temperature although there was no increase in sweat production. On the other hand, Lobitz and Osterberg (1947a) observed low concentrations of chloride in profuse palmar sweating and higher values in scanty intermittent sweating. If palmar sweat sodium chloride concentration increases with sweat rate and/or skin temperature as in "thermal" 
sweating, then individuals with high sweat rates will cause more corrosion also by virtue of higher salt concentration. This may partly explain the large increases in corrosion at high sweat rates shown in Fig. 3.

Since it is likely that the salt concentration of palmar sweat is an important factor in determining the extent of corrosion, differences in the nutritional state of individuals may also be related to this effect. Although Darling (1948) found no increase in palmar sweat chloride by increasing salt intake, there is evidence that salt restriction can lower the sweat chloride level, at least under conditions of heavy (thermal) sweating (Hancock, Whitehouse, and Haldane, 1929; McCance, 1938; Weiner and van Heyningen, 1952b).

The results presented in Table 2 suggest that components other than sodium chloride produce in comparison very little corrosion, although it is difficult to assess total corrosion by sweat in terms of its separate constituents. There is, however, some indication that artificial sweat solutions with high $p \mathrm{H}$ corrode less than those with low $p \mathrm{H}$. At equal sweat rates it might be expected that "thermal" sweat from males would corrode more than that from females because of higher sodium chloride concentration (McSwiney, 1934; Robinson and Robinson, 1954; Davies and Clark, 1950) and lower $p \mathrm{H}$ (McSwiney, 1934; Blank, 1939; Thurmon and Ottenstein, 1952).

\section{Summary}

The extent of corrosion of mild steel produced by palmar contamination from a number of subjects was compared. There was a variation in this effect both from person to person and with the same individual at different times and this was related to differences in palmar sweat rates. Finger print contamination produced more corrosion than that from the palmar surface.

Corrosion by sweat is mainly due to the sodium chloride content, the concentration of which probably increases with palmar sweat rate. Other sweat constituents produce comparatively little corrosion.

Methods available for reducing the corrosive effect are discussed.

For advice concerning the corrosion aspects of this work I wish to thank Dr. J. C. Hudson, of the Corrosion Advice Bureau, and Mr. E. Ll. Evans, of the Chemical Research Laboratories, Teddington. I am also indebted to the Pressed Steel Co. Ltd. for a specimen analysis of the steel and to Messrs. Rozalex Ltd. for generously supplying barrier cream preparations.

I gratefully acknowledge the helpful suggestions of Dr. J. S. Weiner, the considerable technical assistance given by Mr. J. O. C. Willson, and the cooperation of members of the Department of Anatomy, Oxford, who acted as subjects.

\section{REFERENCES}

Anderson, D. S. (1951), Brit. J. Derm., 63, 283.

Beuerlein, P. (1941). Werkstatt u. Betrieb, 74, 23

Blank, I. H. (1939). W invest Derm 2 . 67.

B.S. 1133 Packaging Code, Section 6 (1953). Temporary Prevention of Corrosion of Metal Surfaces. British Standards Institution London.

Clarke, S. G., and Longhurst, E. E. (1951). In Protection and Electro-deposition of Metals, p. 127. [Department of Scientific and Industrial Research: Selected Government Research Reports, Vol. 3.] H.M.S.O., London.

Darling, R. C. (1948). Arch. phys. Med., 29, 150.

Davies, D. F., and Clark, H. E. (1950). Circulation, 2, 494.

Eisler, S. J., and Faigen, H. L. (1954). Corrosion, 10, 237.

Hancock, W., Whitehouse, A. G. R., and Haldane, J. S. (1929) Proc. roy. Soc. B, 105, 43 .

Hellon, R. F., and Lind, A. R. (1956). J. Physiol. (Lond.), 133, 132 Huff, W. J. (1921). Chem. metall. Engng, 25, 865 .

Kuno, Y. (1956). Human Perspiration [Amer. Lect. Ser. No. 285], Thomas, Springfield, Illinois.

Lobitz, W. C., and Osterberg, A. E. (1945. J. invest. Derm., 6, 63. Lobitz, W. (1947a). Arch. Derm. Syph. (Chicago), 56, 462.

, and Mason H. I Lid., (1948, 827.

-, and Mason, H. L. (1948a). Ibid., 57, 69.

,- (1948b). Ibid,. 57, 907 .

MacKinnon, P. C. B. (1954). J. Obstet. Gynaec. Brit. Emp., 61, 390 , and MacKinnon, I. L. (1956). Nature (Lond.), 177, 799.

McCance, R. A. (1938). J. Physiol. (Lond.), 92, 208.

McSwiney, B. A. (1934). Lancet, 1, 641 .

Randall, W. C.., and Hertzman, A. B. (1953). J. appl. Physiol., 5, 399. Robinson, S., Gerking, S. D., Turrell, E. S., and Kincaid, R. K. (1950) Ibid., 2, 654 .

-. S., and Robinson, A. H. (1954). Physiol. Rev., 34, 202

Sharman, C. F. (1944). Nature (Lond.), 153, 621.

Smiałowski, M., and Ostrowska, T. (1954). Bull. Acad. polon. Sci., Cl. 3, 2,345.

Thurmon, F. M., and Ottenstein, B. (1952). J. invest. Derm., 18, 333. Urmeev, A. I. (i 941 ). Korroziya i Borba s Neí, 7 No. 1, p. 49

Vernon, W. H. J. (1935). Trans. Faraday Soc., 31, 1668 .

Weiner, J. S., and van Heyningen, R. (1952a). J. app. Physiol., 4, 725.

Weiner, J. S., and van Heyningen, R. (1952a). J.app. Physiol., 4, 725.

Yerbury, H. E. (1919). J. Instn elect. Engrs, 57 [Supplement to Vol. 57], i18. 